International Journal of Child, Youth and Family Studies (2016) 7(1): 104-124

\title{
THE SPECTRUM OF VISIBILITY: YOUTH EXPERIENCES OF MARGINALIZATION AND HOMELESSNESS
}

\author{
Jane Robson, Lynda M. Ashbourne, and Kevin De Leon
}

\begin{abstract}
In this paper, we present some of the results of a youth participatory action research (Y-PAR) project that involved youth aged 16 to 20 who reported being marginalized in their community, primarily due to a lack of stable or consistent housing. Participants met in weekly group meetings to explore the influences of structural violence on their lives. The participants used arts-based methods to express their experiences of inclusion and exclusion, the influences of structural violence in their lives, and how they see those factors contributing to their ability to influence their own visibility in their communities. Themes in their visual arts projects highlighted aspects of visibility of marginalized youth. Youth participants described visibility as both a positive and negative attribute, depending on the youth's need for resources or support. We include examples of the participants’ arts projects to demonstrate these themes and descriptions.
\end{abstract}

Keywords: structural violence, homelessness, youth, arts-based research, youth participatory action research

Jane Robson is a $\mathrm{PhD}$ candidate in the Department of Family Relations \& Applied Nutrition, University of Guelph, 50 Stone Rd. E., Guelph, ON N1G 2W1. E-mail: robson@uoguelph.ca

Lynda M. Ashbourne, PhD (corresponding author) is an Associate Professor in the Department of Family Relations \& Applied Nutrition at the University of Guelph, 50 Stone Rd. E., Guelph, ON N1G 2W1. E-mail: lashbour@uoguelph.ca

Kevin de Leon is a Master's student in the Department of Family Relations \& Applied Nutrition, University of Guelph, 50 Stone Rd. E., Guelph, ON N1G 2W1. E-mail: kdeleon@uoguelph.ca

Acknowledgements: This project was supported with funding from the Canadian Institutes of Health Research. This paper is part of the CIHR Team grant "Promoting Health through Collaborative Engagement with Youth in Canada: Overcoming, Resisting, and Preventing Structural Violence" conducted under the leadership of Dr. Helene Berman, Western University. A full list of team members can be found at www.voicesagainstviolence.ca. This paper is made possible through the contributions of the six youth who participated in the group discussions and arts-based productions. 
International Journal of Child, Youth and Family Studies (2016) 7(1): 104-124

This youth participatory action research (Y-PAR) project involved youth aged 16 to 20 who reported experiences of marginalization related to inconsistent or unstable housing. A lack of consistent or stable housing can be identified by accommodations that lack security of tenure, couch surfing, living temporarily with others, transitional or interim housing, living temporarily in institutional contexts, or living without permanent housing arrangements (see examples in Gaetz, Donaldson, Richter, \& Gulliver, 2013). The presented feedback explores youth experiences of visibility and invisibility. The youth reported that they were most visible when they were acknowledged in the community, were able to access support, or felt safe. They felt least visible when they were not acknowledged, were unable to access support, or did not feel safe. The youth explained that support systems, community networks, and personal resourcefulness were factors that they felt youth could control to make choices about when and how they wanted to be visible in the community. The participants portrayed the media, socioeconomic class, financial resources, police, city planning, and geography/space in urban areas as factors that they could not control and that influenced the degree to which they felt exposed, safe, or unsafe. This small group project was part of a larger research program ${ }^{1}$ exploring the everyday experiences of diverse groups of young people in Canada in relation to the implicit and explicit influences of structural violence, how it affects their health and wellbeing, and what strategies they use to resist it. The primary focus of this paper is visibility, which was one of the main themes that emerged in visual artwork and group discussions.

\section{Literature Review}

Structural violence refers to those social and institutional practices that produce and maintain pervasive and enduring inequalities between groups of people (DeVerteuil, 2015; Gil, 1999), obstruct persons from accessing resources and reaching their full potential (Galtung, 1990) and violate human rights (Jeong, 2008). Understanding the influences of such systemic oppression requires attending to subtle patterns of exclusion and marginalization. These subtleties manifest themselves through language, religion, ideology, gender, class, ethnicity, and other markers of social identity. Systemic inequalities between groups can serve to normalize this violence, erasing its political and social origins so it is seen as an inevitable and natural consequence of individual choices or characteristics (Gatlung, 1990). This study's construction of structural violence is derived from these ideas, and suggests that the imposition of gendered, class-based, or racialized social hierarchies, in various contexts and formations, serves to produce violence that socially and culturally marginalizes individuals’ opportunities for emotional and physical well-being.

Although the number of homeless individuals is difficult to ascertain, it is estimated by the Homelessness Partnering Secretariat of Canada that 150,000 to 300,000 individuals in Canada experience homelessness every year. Further, it is estimated that youth make up 20\% of

${ }^{1}$ Promoting Health through Collaborative Engagement with Youth in Canada: Overcoming, Resisting and Preventing Structural Violence (PI Dr. Helene Berman), renamed "Voices Against Violence" by our National Youth Advisory Board, is funded by Canadian Institutes of Health Research (2011-2016). See website at www.voicesagainstviolence.ca. 
International Journal of Child, Youth and Family Studies (2016) 7(1): 104-124

that population (Gaetz, Donaldson, Richter \& Gulliver, 2013). Literature on youth who have experiences of unstable or inconsistent housing is largely focused on the health and social consequences of unstable housing, drug and alcohol misuse (Boivin, Roy, Haley, \& Galbaud du Fort, 2005; Hwang, 2001), and young people's participation in frequent at-risk behaviours (Karabanow, 2010) such as criminal or risky sexual activities (Votta \& Manion, 2004). Youth who are deemed to be at risk or engaging in risky behavior are often seen as the authors of their own misfortune (see Kidd, 2007).

Communities across Canada continue to be challenged by the increasing number of individuals who experience inconsistent and unstable housing (Gaetz, 2013). In Ontario, the provincial government has attempted to move toward long-term approaches to homelessness rather than focusing on short-term emergency responses that have proven to be difficult to sustain. Some of the more recent initiatives developed in Ontario include the Expert Advisory Panel on Homelessness, which provides recommendations to reduce ongoing and chronic homelessness; the Community Homelessness Prevention Initiative, which grants increased funding to municipalities for homelessness programming; and the Canada-Ontario Investment in Affordable Housing Agreement (IAH), which contributes to the development and maintenance of numerous affordable housing units (Ontario Poverty Reduction Strategy, 2014). Although these initiatives are beginning to shift policy and practices, researchers suggest that there is still a need for youth-focused prevention strategies. Such proposed strategies include: multifaceted assessments in youth integrated systems (Gaetz, 2013); outreach programs and funding rooted in communities, including specialized services for subsets of the population (Springer, Lum, \& Roswell, 2013); and enhanced transitional programming for youth exiting institutional care (Nichols, 2013).

Gaetz (2004) suggested that one of the most likely experiences that youth with unstable housing will encounter is social exclusion. Social exclusion may occur across several domains such as housing, shelter (protection from the elements), employment, or education. Youth may be denied participation in economic, social, or cultural aspects of society (Arthurson, 2003; Robinson, 2013; Silver \& Miller, 2003), which negatively affects their quality of life and wellbeing (Levitas et al., 2007). Youth who have experienced inconsistent or unstable housing may undergo a cumulative process of exclusion, which can result from a lack of ongoing care and nurturing relationships (Kelly \& Caputo, 2007) and intensifies as youth are exposed to the risks that accompany unstable housing. Their lives often take place in a public environment in which their movements are constrained and they have limited opportunities to control the people, places, or activities that surround them (Gaetz, 2004). Consequently, the subsistence strategies they utilize may directly impact the risks that they are exposed to on a day-to-day basis, and thus their immediate safety and well-being (see Frankish, Hwang, \& Quantz, 2005). These strategies can cause youth to disengage from mainstream services (Baron, 2001) or reject assistance from others (Kelly \& Caputo, 2007).

Other researchers have explored the experiences of children and youth when accessing social service delivery systems. Ungar (2006) found that these children and youth go through a dual process of navigating and negotiating in order to locate resources and services. There is little research regarding the influence of power, marginalization, or personal agency of the children and youth accessing social services; rather, some have suggested that the main focus has been on intervention and outcomes (Karabanow, 2010; Ungar, 2005). Ungar (2005) argues that 
International Journal of Child, Youth and Family Studies (2016) 7(1): 104-124

researchers need to spend more time engaging with the youth who access these services, and considering how their personal agency influences their ability to access social resources and supports. This could provide an opportunity to explore how at-risk youth can mobilize resources to become resilient in their communities and manage experiences of unstable housing.

\section{Current Study}

The current study is part of a larger national research team project utilizing youth participatory action research (Y-PAR) methods to examine the ways in which structural violence is woven into the everyday lives of young people. Across the larger team project, various Y-PAR groups were conducted with diverse groups of marginalized youth. In order to extend our knowledge of youth who are deemed to be at risk of victimization, lack of access to services, or other forms of marginalization and exclusion due to their experience of homelessness and poverty, the current study examines the day-to-day influences of structural violence in collaboration with young people who have experienced unstable and inconsistent housing. During this research project, we invited the youth participants to reflect on how they understand structural violence, its influences in their lives, and how they might respond to these influences.

\section{Disclosure}

I, first author, am a white female graduate student in my late 20s who lives in stable housing, attends university, and works as an attachment and trauma family therapist in the same community as our participants. I, second author, am a white academic researcher and family therapist in my 50s, and a co-investigator in the larger research project team. While I have worked with diverse marginalized and mainstream client populations in rural and urban settings as a family therapist, my relative privilege and age means that I am quite different from these participants. I served primarily in an advisory capacity during data collection and analysis, although I also attended one meeting in order that the participants would have a sense of who I was as a person rather than simply as a "removed researcher". I, third author, am an AsianCanadian male in my late 20s who lives in stable housing and attends university in the same community as our participants.

\section{Method}

Participatory action research (PAR) is grounded in the ideas that the world is transformable, and that people can actively participate in the world as change agents (Flicker et al., 2008). PAR research recognizes the power of collaboratively produced knowledge (Cahill, 2007), where participants are viewed as knowledge experts, and their lives and experiences are integral to shaping questions and framing interpretations of the research (Torre \& Fine, 2006). More specifically, for the purpose of this study we used Y-PAR, which encourages youth engagement in social research (Ozanne \& Saatciogul, 2008), gives voice to youth concerns (Cammarato \& Fine, 2008), and invites social action (Cahill, 2007; Newbury \& Hoskins, 2012; Powers \& Allaman 2012), in an attempt to engage with individuals whose lives are directly affected by the issues under study (Bradbury \& Reason, 2003). Rather than conducting research "on youth", Y-PAR allows us to conduct research "with youth” — co-researching local and contextualized knowledge, and considering what change might follow from enhanced critical consciousness. Y-PAR is a tool that generates youth leadership and youth enthusiasm for social justice and community change (Cammarato \& Fine, 2008). This methodology enables space for 
International Journal of Child, Youth and Family Studies (2016) 7(1): 104-124

critical reflection and has empowering potential that may contribute to change either at the individual level or at broader structural and social levels.

After obtaining institutional research ethics approval from the University of Guelph, we recruited a total of 13 youth between the ages of 16 and 24 years for this arts-based Y-PAR study in a mid-sized urban centre in south-central Ontario, Canada (population approximately $120,000)$. The inclusion criteria for participating in the project were that the youth had to be 16 to 24 years old and report experiences of unstable or inconsistent housing. Our recruitment methods included meeting with local community partners who provide direct services to young persons, such as youth shelters, alternative education programs, and drop-in centres. These community partners posted recruitment posters at their agencies, and some agencies allowed us to be on-site during programming in order to speak with youth.

In our first meeting with the youth we explained the purpose of the project, shared various ideas and definitions regarding structural violence, and answered the youth's questions about the project. Not all of the recruited youth were able to continue to attend the research group, and the final group comprised six persons, three females and three males ${ }^{2}$, ranging in age from 16 to 20 years. The youth who participated in this project stated that they had experiences of housing instability or homelessness ranging from direct personal experience to supporting someone else in their life through an experience of inconsistent or unstable housing. These participants were also socially and economically disadvantaged. For example, all of the youth participants were receiving supports at the time of the research group or in the recent past from child welfare agencies, food banks, local shelters, and youth drop-in centres. Experience of inadequate housing was self-identified as among the most salient characteristics of these youth at the time of recruitment. At the time of the research project, two of the participants were finishing high school, two had dropped out of high school, and two were in alternative education programs. They reported living arrangements at the time of the group that included living at home with their parents, renting space, and living in youth shelters. Sexual orientation and ethnicity or racialized identity were not explicitly noted by participants at the time of recruitment.

Attendance at weekly group meetings over the course of two and a half months was somewhat sporadic and not all the youth were able to attend all the sessions. We believe that this inconsistent attendance reflected some of the complexity and uncertainty in these participants' daily lives (see Gaetz et al., 2013 for examples). The youth did not all have phones or someone else in their living space to wake them up in the morning.

The participants attended weekly three-hour Y-PAR sessions for a period of ten weeks co-facilitated by the first and third authors. Participants were paid $\$ 10$ an hour (\$30 a session) at

${ }^{2}$ Although it was not explicitly noted by the youth participating in this project, the literature suggests that the gender ratio of youth with a lack of stable or consistent housing is roughly two males on the street for every female (O’Grady \& Gaetz, 2009) and that Aboriginal youth (Belanger, Weasel Head, \& Awosoga, 2012: Higgitt et al., 2003) as well as lesbian, gay, and transgendered youth (Abramovich, 2012) are more likely to have unstable or inconsistent housing. 
the end of each group session attended. The Y-PAR sessions typically began with a check-in, and preliminary discussion about topic areas determined by group members' recent experiences of structural violence. The youth and facilitators used the original definitions of structural violence discussed in the introductory meeting to collectively brainstorm ideas regarding structural violence, how it is defined, and in what ways it is present in the youth's lives. These conversations would build on discussions from previous meetings and preliminary ideas regarding structural violence that were introduced in the first group meeting by the group facilitators. Discussion and arts-based activities followed from these topic areas. The arts-based activities drew from the interests of the participants, and the group worked together to brainstorm two or three options before selecting what they wanted to do. These discussions were conducted collaboratively in order to generate youth leadership and enthusiasm (Cammarato \& Fine, 2008). During these sessions, group facilitators and participants made notes of themes, quotes, or other information that emerged; incorporated multiple voices in the data; and provided space to acknowledge that "no one voice can be characterized by one perspective" (Newbury \& Hoskins, 2008, p. 228). The group facilitators and youth checked in with each other following group conversations to discuss whether all of their views were being expressed, whether the individuals felt their ideas were being captured, and whether the focus of the group was fitting with the youths' own experiences. These check-ins served to ensure that the knowledge generated and documented was collaboratively produced (Cahill, 2007).

In the Results section, we present the participants' artistic expressions and reflective comments made during group discussions, as recorded in writing by facilitators and youth participants during each meeting. These represent the participants' observations of structural violence, marginalization, the effects of inconsistent or unstable housing, and their experiences of various degrees of visibility in their communities. The three authors of this paper selected the themes and observations by reviewing all of the artwork and group notes after the group had finished. Member-checking occurred in the form of ongoing checking with participants during the course of group meetings, including conversations about how they would like their ideas and thoughts captured in writing and their artwork presented. We were unsuccessful at memberchecking after the group meetings were completed. We used various means to try and contact the youth to discuss the selected themes but did not hear back from them after numerous attempts. It was evident while the group was wrapping up that following up might be difficult due to complexities such as hospitalization, residential treatment programs, and a general lack of access to the Internet. These barriers are addressed in our Limitations section. The presented findings speak to the notion of visibility, a prominent theme proposed by participants in art production and dialogue. Pseudonyms are used throughout to denote participants, with the exception of Devin, who explicitly requested that his name be included with his quotations, artwork and photos.

The youth used a variety of arts-based methods in examining their experiences and considering their social responses. The methods included painting, collages, drawing, comic strips, community mapping, self-portraits, and mask-making. These activities were used in a variety of ways to facilitate reflection on the influences of structural violence and marginalization, and to express personal life-experiences. Drawing comic strips provided an introduction to ideas related to structural violence and participants' experiences, and allowed participants to explore the political climate of their experiences. Producing collages about structural violence in the community, especially as related to homelessness, allowed an 
exploration and expression of the varied dimensions of these influences. Creating paintings on the theme of the roots of structural violence allowed the youth to illustrate what systems contribute to marginalization and exclusion, and how these influences might be seen in society. The youth also completed maps using the technique of community mapping, a data collection and communication tool based on constructing maps of different neighbourhoods in order to identify capacities, abilities, gaps, and assets (Amsden \& Ao, 2003; Amsden \& VanWynsberghe, 2005). The youth used these community maps to explore and describe spaces they experience as safe or unsafe, as well as how they experience their own visibility in the community. Selfportraits provided expression of how individuals are affected by structural violence. The multiple faces of structural violence were expressed through mask-making.

A photovoice project was the final arts-based project decided upon by the youth participants. Photovoice is a tool used to support participants in capturing their experiences through photographs. Using this mode of observation and expression encourages participants to reflect on community concerns or strengths, day-to-day lived experiences of marginalization, and influences of structural violence; it also promotes critical knowledge and dialogue regarding community issues (Catalani \& Minkler, 2010). This methodology has been used with a range of populations who have experiences with marginalization (Castleden \& Garvin, 2008; Graziano, 2004; Harley, Hunn, Ellio, \& Canfield, 2015;Wang, Cash, \& Powers, 2000) and is particularly useful for youth-based research because it is not constrained or mediated by language and is often more attuned to youth culture (Rudkin \& Davis, 2007). This methodology enables dialogue that reaches more nuanced aspects of experience, which may not be accessed through direct questioning (Leitch, 2006). In photovoice, participants are taught how to use cameras creatively and usually work together to generate a theme to be the focus of their photos (Newbury \& Hoskins, 2008). In this project, each youth collaborator was given a camera and some basic photography training, and spent three weeks taking photos in the community. The group decided to take photos related to the common themes that were contained in the group discussions over the course of earlier research meetings. The participants chose to take pictures that they felt represented their understanding of structural violence, homelessness, and class. These photos were brought back to the group, discussed, and organized into a photovoice presentation. The group worked together to decide which photos to include in the photovoice project, based on the messages the group members felt the photos conveyed and how these messages fitted into the overall presentation. Typically, the final step of photovoice involves sharing the photos or presentation with decision-makers, community members, or policymakers in the hopes of influencing social change (see Carleson, Engebretson, \& Chamberlin, 2006; Wilson et al., 2007). The youth in this group shared an interest in having their presentation viewed by city council, in schools, by social service employees (such as social workers or probation officers), and by decision-makers in the community.

\section{Results}

The youth involved in this group pointed to their own experiences of visibility as evidencing structural inequities and social marginalization. They made a distinction between being “actually seen” versus being "looked through" by others in the community. They described institutional practices that rendered them invisible and did not take their needs and current context into consideration. They pointed to the ways in which they attempt to manage their visibility by presenting themselves in certain ways and their awareness of how media and social 
International Journal of Child, Youth and Family Studies (2016) 7(1): 104-124

norms influence how others see them. In addition, these youth described their own acts of resistance to being rendered invisible by making connections with others to build on their own resources.

\section{Being “actually seen" or "looked through"}

The participants in this group described visibility as an important aspect of experiencing or witnessing homelessness. They described a spectrum of visibility that included feeling safe or feeling unsafe based on the positive or negative gaze of others. These youth defined visibility as being "actually seen” rather than "looked through.” Devin talked about his experiences of homelessness and how many people would walk by him on the street as if he did not exist. He shared with the group that he wanted to tell everyone walking by him, “Don't look through me. I am here. Treat me like a person, not an animal.”

Experiences of visibility were differentiated by these youth based on how, when, and whether they felt they were acknowledged in interactions with others in the community. They described experiences of sitting on the sidewalks downtown and having individuals they did not know make some sort of visual contact (eye contact, waving) or verbal contact (saying hello, asking them to move). The participants stated that they felt most visible when they initiated contact with others to gain support and were successful in obtaining a positive response. In comparison, they suggested that they felt least visible when people on the street looked at them but did not appear to register their presence, or looked past them without changing their demeanour. Devin described sitting on the street and reaching out to an adult passing by for help. He stated that he was told to get a job, get off the streets, and to move out of the way. He explained that he felt insignificant in the face of this response, and that this was a form of negative visibility because, although he had reached out to a stranger, he was no further ahead in obtaining support.

The participants in this study stated that they did not always have a choice regarding whether they were visible or invisible in their communities. Being visible could lead to being exposed or unsafe; there were times that they did not necessarily want to be seen. Heather gave the example of having difficulty finding a place to stay cool on a hot summer day. She explained that she had stepped inside a store to cool off but immediately after entering the store she was asked to leave by the owner. Heather felt that she was asked to leave because of her clothing, and how she looked, and felt that the store owner may have guessed that she wasn't able to purchase anything in the store. In terms of safety, youth described how challenging it was to find a safe space during the day. The youth discussed numerous public spaces such as a few particular parks downtown, and described how they had no control of who came in or out of such spaces, creating a sense of unpredictability regarding their own safety.

The participants suggested that, because of their clothing, how they looked that day (e.g., if they were able to shower), or where they passed time in the community (e.g., downtown or at a drop-in centre), youth who were experiencing unstable or inconsistent housing were often assumed to be of a lower class than others. Heather talked about having to hang out downtown during the day and that there were always “creepy men and weirdos” approaching her. She talked about times when men downtown had approached her asking for drugs or trying to befriend her or convince her to use drugs with them. Grace suggested that when people judged that she was of a different - lower — class, either from conversation or appearance, they would treat her 
differently. She gave an example of a woman with children crossing the street rather than walking past her on the street. In the comic shown in Figure 1, Heather drew two sections: individuals who consider themselves part of a higher class, and individuals who consider themselves part of a lower class. She separates these two types of classes and suggests that those who see themselves as higher class ignore and discriminate against those they see as lower class. She describes individuals who are a part of the lower class as more inclined to support one another by sharing resources.

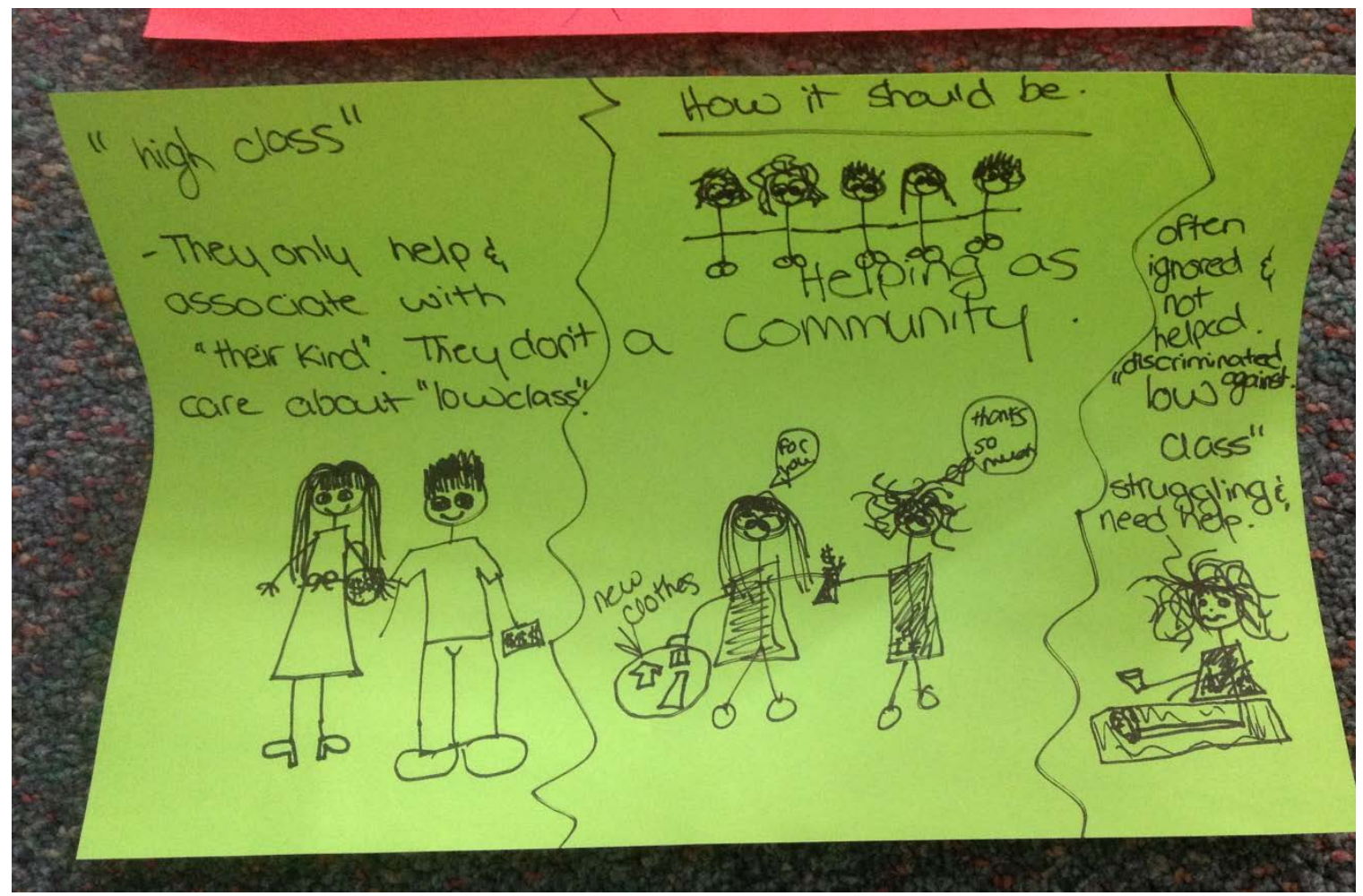

Figure 1. "Comic of experiences of violence”.

\section{How Youth are Seen by Institutions}

These participants described institutions as having significant influence on their experiences of visibility and marginalization. They discussed how being involved with systems such as probation, the Children's Aid Society, the education system, shelter systems, or various levels of government had made them realize how exclusion or feeling invisible had become "normal, it's everywhere and no one seems to be doing anything about it" (James). The group provided examples of these systems making them feel invisible, such as probation workers forgetting to call to check in regarding a curfew (Kris), or a social worker at the Children's Aid Society calling Heather by the wrong name after years of being her case worker. The youth described structural violence as "the people in power making decisions" (Grace) with "different priorities" (Kris) than their own. The youth gave examples of the mayor and city council making a decision to move the bus terminal away from downtown to get rid of the "dirty downtownies" (Heather) who hung around the bus terminal, who were described to be youth who had experiences of unstable or inconsistent housing. The youth described the implications of these decisions on their visibility in the community. Devin suggested that by moving the bus terminal away from downtown, community members wouldn't have exposure to youth who are homeless, 
International Journal of Child, Youth and Family Studies (2016) 7(1): 104-124

and this could lead them to believe it was not a problem or that they did not need to help. James expressed his frustration at the messages being given by city decision-makers, and there was a general consensus that these efforts could be causing the issue of unstable housing to be invisible to community members.

Systems, such as the city, were described by youth participants as being at the root of structural violence (see Figure 2). Grace stated, "I am not sure I even notice it anymore, it's ingrained in our society." The group members discussed how social service systems or the government "have the power to be selective about bringing attention to only certain kinds of structural violence” (Grace) and that "it's not about us, that's not as important” (Kris). They talked about how challenging it was to obtain food or shelter and their frustration over the fact that, to their knowledge, these issues weren't ever the focus of the mayor or city decisionmakers.

Kris described his ongoing interactions with his probation officer, and suggested that, “It's not natural, they are paid to look into me. So I know they don't care about me or what I do. They don't hear me." The youth agreed that these systems interacted with them like they were "just another face" (Lauren) or "just another number on their caseload" (James). Heather was sick with a chest infection for part of the group, and when attempting to reach her social worker during a group break in order to get her health card to fill her prescription, she was redirected four times to four different workers and the call was eventually disconnected at the other end. The participants agreed with each other that this was a typical chain of events and that, even after being in care for over a decade, the social worker "doesn't even know us or remember us" (Heather). Devin gave an example of his teacher suggesting that to live a healthier lifestyle he should start going to the gym. He explained, "I don't even know where I am going to sleep tonight, so jumping on a treadmill didn't seem important” (Devin). He described his frustration with the fact that a teacher could be so out of touch with a student's needs or background, and how misunderstood he felt during this conversation.

The youth talked about systems, such as the shelters, following procedures and protocols that prevent youth from feeling visible or able to control their day-to-day activities. Heather, who was living in a youth shelter for the duration of the group, talked about how young people were not allowed inside the shelter during the day. She expressed her frustration about having to be gone in the day by 9 a.m., and most public places not opening until 10 or 11 . She described "freezing to death" sitting outside during the winter, waiting for stores or the mall to open after leaving the shelter in the morning. The youth talked about how the shelter system may be one of the reasons that "homeless people get into trouble, what else are they supposed to do during the day” (Devin). Heather stated, "Instead of having a home, it's [the shelter is] just a place that people let you sleep at night." She expressed her frustration with explaining this situation to the workers at the shelter and being told that it is a policy that youth cannot be inside during the day and there is nothing the workers can do about it. The youth expressed how these sorts of procedures or protocols caused youth to feel less visible, and to generalize that any youth staying in shelters were not trustworthy enough to be indoors during the day. Heather asked, "What if I was different? And why doesn't that matter?” The youth discussed how they should have an opportunity to prove themselves before being made to feel invisible by having to stay outdoors all day because of policy or protocols. 


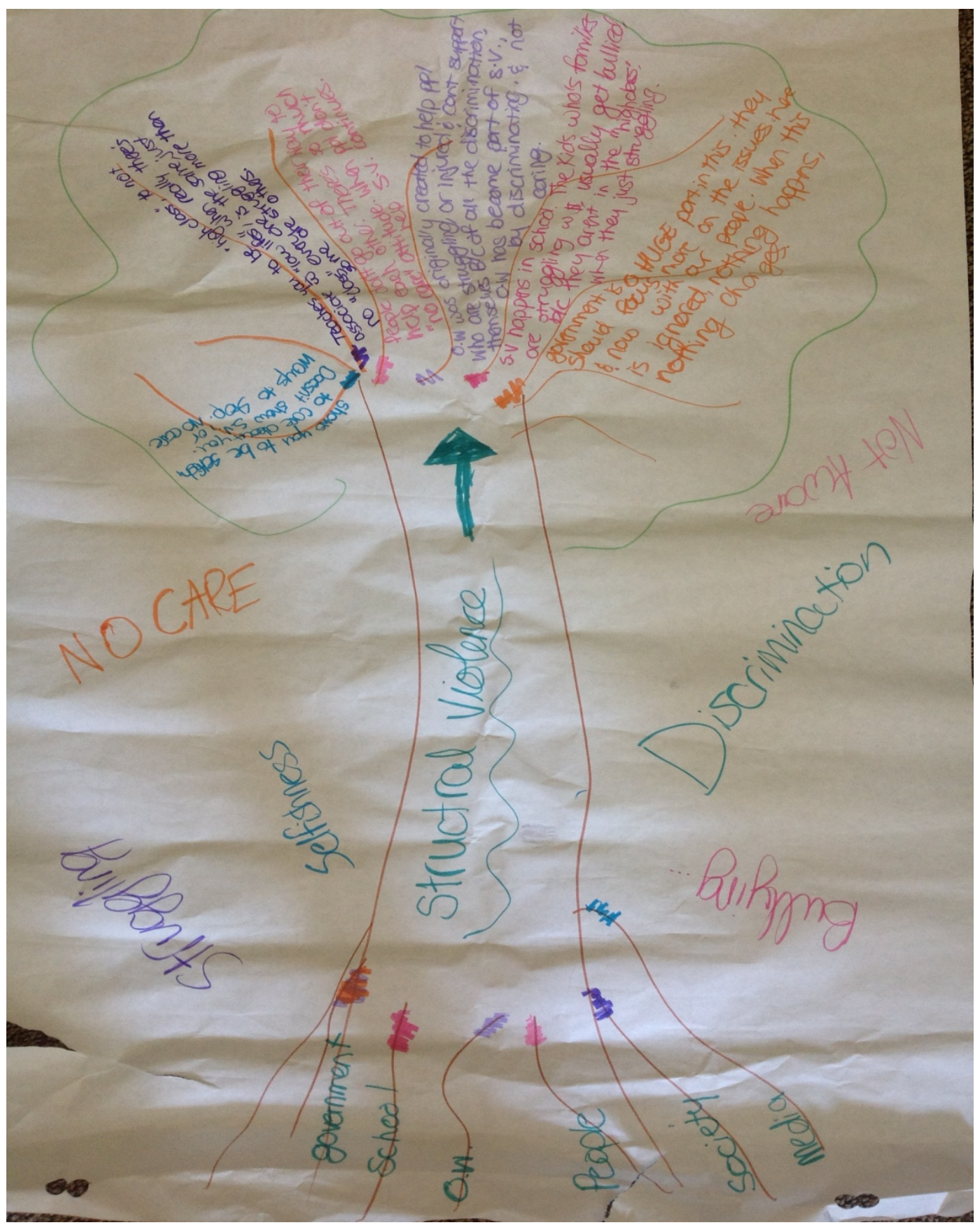

Figure 2. "The roots of structural violence".

The youth also described how certain agencies made them feel visible and like they belonged. The youth described one particular community centre downtown, where the staff knew them and where they were welcomed upon entering. Grace discussed how this was a place that staff supported you even though they were aware of your circumstance (unstable housing, on the 
International Journal of Child, Youth and Family Studies (2016) 7(1): 104-124

streets, recovering from addiction). Heather talked about how this particular centre protected youth, by doing "more than they have to." Devin stated that when he was living on the streets a worker gave him permission to use the centre's phone number as his contact information. He would attend the centre when he could and the staff would pass along voice messages from his family, case workers, or landlords of potential apartments. The youth discussed how having someone who knows your name, or recalls what you had previously told them and asks about it, can make youth feel safe and appreciated.

\section{Youth Presenting and Resisting Visibility}

These youth discussed how their sense of being visible could influence their ability to make connections to obtain support. For example, they described ways that they could influence their visibility by being selective about where they chose to stay, what they chose to wear, or how they presented themselves in a particular situation. In times of need, they suggested that their choices about presentation could elicit support such as food or shelter from community members or professionals, or these choices could lead to upheaval, fights, or judgement. Devin suggested that, even though they could make choices about how to present themselves, there was always a sense of unpredictability when initiating an association with others. For example, Devin stated that when he was sleeping on the street he got to know one of the police officers that worked nights. He said that he and the police officer would chat and ended up getting along fairly well. Devin further explained that, because of this, eventually the police officer told him how to "rotate locations." He said that he learned that he was able to sleep in certain areas on certain nights without being monitored or told to relocate by the police. However, he acknowledged that the degree of agency to influence his visibility was still limited. The police officer could still arbitrarily decide to change the monitoring schedule or a community member could call in a complaint about someone sleeping in a public place.

The youth also described not always having choices about being visible. Heather gave an example of staying on the floor at a "drug house" because she was did not have stable housing at the time and a friend of hers was staying there. Heather stated that one of the nights she was staying at the home there was a police raid, and she was arrested with the other individuals in the home. Heather described having to stay in jail overnight. She explained that although she had made the choice to sleep at the drug house, she had no choice about being arrested and "lumped in" with the individuals in the home dealing or using drugs. Heather stated that, in this circumstance, she would have resisted visibility if possible, but based on the fact that she was sleeping on the floor in the home, the police assumed her to be "just like the rest." Devin suggested that if Heather had a private apartment to sleep in, she wouldn't have to worry about her own visibility because she could choose who would be welcome in her apartment and would not have to associate with individuals involved with drugs.

These participants also suggested that other youth taught them about choosing their visibility levels by providing information and resources regarding community centres, or certain shelters in the community that were more welcoming, understanding, and staffed by people who "want to help, that can help you make change" (Devin). As suggested by the image presented in the final photovoice photo (Figure 3), the youth stated that "there's safety in numbers" when connecting with others who have similar experiences of unstable housing who can "teach you where to eat, where to sleep, and what to do" (Devin). 
International Journal of Child, Youth and Family Studies (2016) 7(1): 104-124

\section{Safety in numbers}

\section{CAME HERE TO SLEEP ONE NIGHT AND FOUND EIGHT PEOPLE SLEEPING IN THIS CUBBY HOLE.}

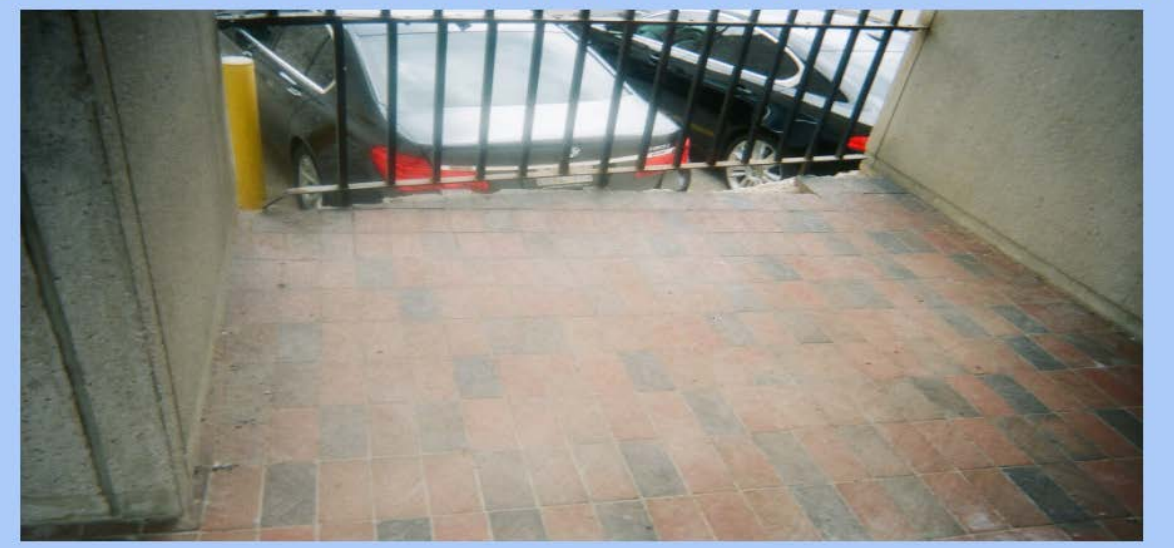

Even in homelessness, there's safety in numbers.

Figure 3. "Safety in numbers".

The youth participants explained that they could sometimes choose when to participate in the support systems they deemed helpful or when to access resources. Grace gave the example of the police attending a community centre looking for drugs, or drug dealers. She heard about what had happened through a friend and made a choice to stay away from that particular centre until things had settled down. She described feeling personally resourceful in making that decision and staying away so she didn't get associated with the individuals causing problems. In this case, Grace made a choice not to be visible at the community centre.

The participants explained that over time they would learn how to be resourceful on the street. Devin stated, “At first it was hard, I was cold, I couldn't find food but after a while I got used to it. You learn where to sleep. You learn where you can get food.” He explained that, over time, he learned to keep a backpack, water bottle, and blanket ready at all times, in case he chose to leave the shelter at the last minute or if there was trouble and he needed to get away. Although Devin could not control when trouble might arise at the shelter, he did describe choosing to be prepared to become less visible if necessary. He drew a self-portrait of structural violence (Figure 4) in which he stood alone in the cold with a backpack, water bottle, and blanket beside him. He explained that he didn't know in this instance where the road was going and that, as a person who experienced homelessness, he never knew where the road was going. 


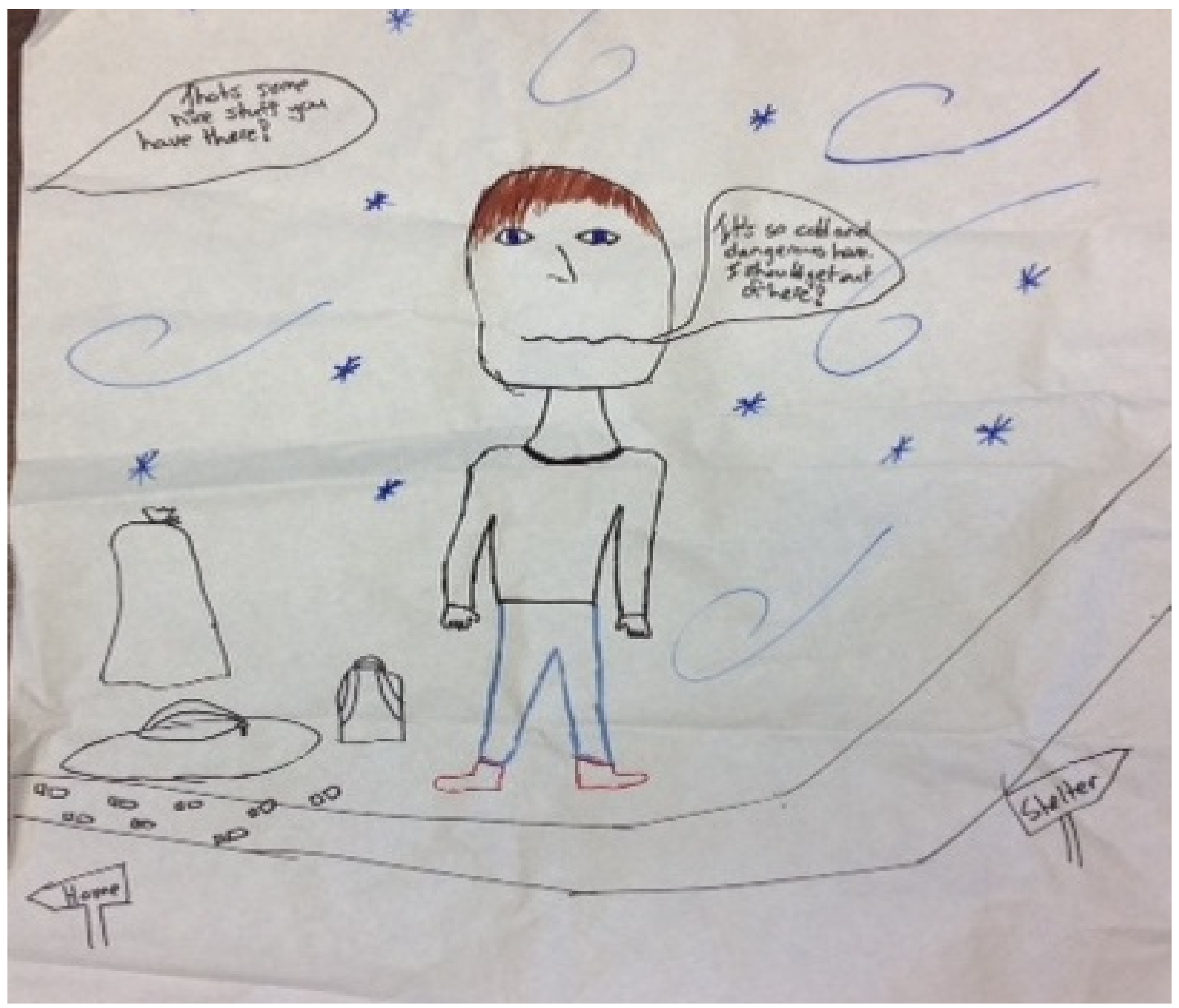

Figure 4. "Self portrait of structural violence". Captions read, "That's some nice stuff you have there!” and, "It's so cold and dangerous here. I should get out of here!” The directional signs say "Home" and "Shelter".

The participants identified the media as another structure that influences their visibility and the ways that they should be visible. James suggested that social media shapes the stories society hears about youth, and can influence which stories are most commonly shared. This, in turn, influences how individuals choose to present themselves. Kris added that the media reinforces stereotypes about how youth should look. For example, Grace pointed to female teenagers in the media being skinny, blonde, and wearing nice clothing. These youth explained that this set a standard regarding how youth should look and present themselves in society, which wasn't always attainable for them due to a lack of resources, leading to youth feeling invisible or unsafe. Heather talked about how she could not afford to wear the clothes presented in the media, and other group members talked about how difficult it was to maintain good hygiene when experiencing unstable or inconsistent housing. In the photovoice presentation, the participants used the following photo (Figure 5) and description to exemplify how they saw media influencing their visibility. 


\section{The media influences the general population. It tries to overall mould us into a perfect image.}

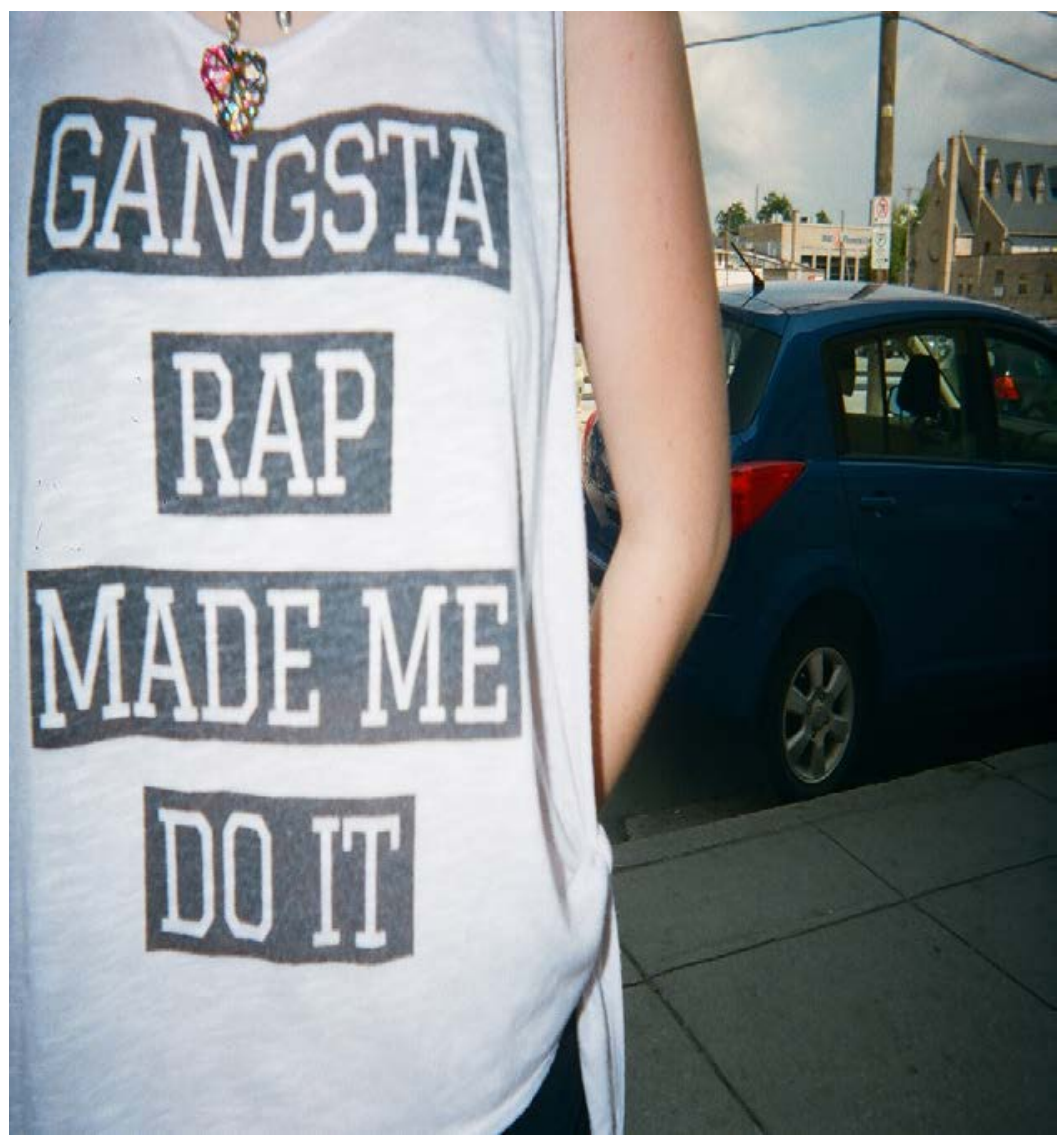

Figure 5. "The media influences the general population”.

\section{Discussion}

The participants in this Y-PAR group, sharing experiences of unstable or inconsistent housing, provided us with an instructive picture of how they believe that they are "actually seen" or "looked through" by others when they are in the street; their experience of being seen by institutions and systems in certain ways that are reflected in policies and protocols; and how they see themselves presenting or resisting visibility in order to promote their own well-being and safety. The artwork and discussions that these youth collectively produced provides us with direction for further action in this area and for the education of those who interact with youth in their day-to-day work. These youth talked about how beneficial it would be for young people who attend agencies such as Ontario Works or the Children's Aid Society to provide a workshop regarding how services can support youth who are experiencing marginalization. They also suggested that more attention should be paid to urban spaces and institutional practices that can serve to exclude persons and exacerbate risk to personal safety. The Y-PAR participants suggested that city decision-makers could spend time in some of these urban spaces, and consult with the youth who use these spaces regarding the impact of making changes to them.

These youth provided examples of social exclusion (Gaetz, 2004) in their feelings of visibility (or invisibility) in their communities. In particular, they pointed to the gaze of others, as well as specific institutional practices that served to exclude them. Although Gaetz (2004) described a cumulative process of exclusion, in which youth implemented subsistence strategies 
that increased their levels of risk over time, the youth participating in this study described becoming progressively more "street savvy". They indicated that they were thus able to make choices that enhanced and increased their levels of safety, such as learning where to obtain food on weekends or what areas of downtown to stay away from at certain times. These youth described learning from others, over time and through repeated experiences of having unstable housing, about how to exercise control over the choices they were making in regards to how they presented themselves, where they spent their time, whom they associated with, and what kind of relationships they formed. In contrast to a narrative suggesting that "at-risk" youth put themselves at more risk by associating with the "wrong crowd" or by engaging with deviant peer associations (Whitbeck, Hoyt, Yoder, Cauce, \& Paradise, 2001), these findings suggest that there may be times when such associations build positive collective resources and lead to social inclusion. This challenges some taken-for-granted views of who or what constitutes a positive association. The youth spoke fondly of relationships they had formed with other youth who were experiencing unstable housing and who had an understanding of such experiences. It was evident that these relationships not only enabled the youth to be visible but also gave them some of the knowledge or resources required to make choices regarding their own visibility.

These youth demonstrated their capacity to be resilient in a challenging context and mobilize resources in their community to manage unstable housing. This fits with Ungar's (2005) findings that youth undergo a dual process of navigating and negotiating resources. It also extends Ungar's (2005) findings by providing suggestions for how service providers could support youth navigating and negotiating social service systems. The participants emphasized the importance of service providers getting to know the youth and their circumstances, spending time "understanding who we are" (Kris). They explained that this could foster a trust between services and young clients that would enable youth to feel more visible, and more confident about reaching out to social service agencies for support. Another important consideration is the high rates of staff turnover evident in social service sectors, specifically with service providers who have opportunities to engage with youth experiencing unstable or inconsistent housing (Daiski, 2007). This may contribute to some of the youth's frustrations regarding a lack of connection or consistency with their social workers, teachers, or probation officers.

The youth participating in this project were not always able to attend the group. We believe that this reflects the unpredictability and complexity of their day-to-day lives. This in itself is an interesting finding with regard to the ways in which structures and organizations attempting to impose a timetable for participation overlook the obstacles present for those whose lives are not so much governed by a daily or weekly schedule or routine. Further to this, although the arts-based activities and photovoice project inspired the creation of ideas for social action, due to the competing and serious concerns in these youths' lives (for example, hospitalization, admission to residential drug treatment program) it proved impossible to move these plans to action in the time set aside for the Y-PAR group. Similar challenges meant that attempts to maintain ongoing contact with the youth through social media and texting were unsuccessful due to the impermanence of contact information and geographic location. Therefore, to the best of our knowledge, the youth were unable to fully participate in the dissemination of the photovoice project in the ways they had suggested or hoped (such as presenting to city council, or attending a social service agency to present). We would recommend that future projects involve early negotiation of means of connecting after the project is completed, in order to facilitate any 
further action or knowledge sharing that the participants wish. As well, we recommend allocating a longer time frame for a Y-PAR project.

We believe that Y-PAR and arts-based methodologies provided a unique opportunity for us as researchers to collaborate and learn together with youth about their direct experience of structural violence in the context of homelessness, and social and economic disadvantage. The participants described this methodology as enabling them to feel heard, to have a voice ("We were heard, and that's a good thing"), and to think critically about issues in our community. The participants shared that engaging in this research had made them "more aware of what's going on around me" and that they are "looking at the bigger picture now and thinking about how we can change or stop structural violence." 
International Journal of Child, Youth and Family Studies (2016) 7(1): 104-124

\section{References}

Abramovich, I. A. (2012). No safe place to go-LGBTQ youth homelessness in Canada: Reviewing the literature. Canadian Journal of Family and Youth/Le Journal Canadien de Famille et de la Jeunesse, 4(1), 29-51.

Amsden, J., \& Ao, K. (2003). Community asset mapping: Youth in community research. SPARC BC: News from the Social Planning and Research Council of BC, 19, 28-32.

Amsden, J., \& VanWynsberghe, R. (2005). Community mapping as a research tool with youth. Action Research, 3(4), 357-381.

Arthurson, K. (2003, September). A critique of the concept of social exclusion and its utility for Australian social housing policy. Paper presented at the UK Housing Studies Association Conference Bristol, UK. Retrieved from www.york.ac.uk/chp/hsa/papers/autumn03/Arthurson\%20and\%20Jaco bs.pdf

Baron, S. W. (2001). Street youth labour market experience and crime. Canadian Review of Sociology and Anthropology, 38(2), 189-215.

Belanger, Y., Weasel Head, G., \& Awosoga, O. (2012). Assessing urban aboriginal housing and homelessness in Canada. Ottawa, ON: National Association of Friendship Centres \& the Office of the Federal Interlocutor for Métis and Non-Status Indians,

Boivin, J. F., Roy, É., Haley, N., \& Galbaud du Fort, G. (2005). The health of street youth: A Canadian perspective. Canadian Journal of Public Health/Revue Canadienne de Sante'e Publique, 432-437.

Bradbury, H., \& Reason, P. (2003). Action research: An opportunity for revitalizing research purpose and practices. Qualitative Social Work, 2(2), 155-175. doi: $10.1177 / 1473325003002002003$

Cahill, C. (2007). The personal is political: Developing new subjectivities through participatory action research. Gender, Place and Culture, 14(3), 267-292. doi:10.1080/09663690701324904

Cammarota, J., \& Fine, M. (2008). Youth participatory action research. In J. Cammarota \& M. Fine (Eds.), Revolutionizing education: Youth participatory action research in motion (pp. 1-12). New York, NY: Routledge.

Carleson, E., Engebretson, J., \& Chamberlain, R. (2006). Photovoice as a social process of critical consciousness. Qualitative Health Research, 16(6), 836-852. doi:10.1177/1049732306287525

Castleden, H., \& Garvin, T. (2008). Modifying photovoice for community-based participatory Indigenous research. Social Science \& Medicine, 66(6), 1393-1405. 
International Journal of Child, Youth and Family Studies (2016) 7(1): 104-124

Catalani, C., \& Minkler, M. (2010). Photovoice: A review of the literature in health and public health. Health Education \& Behavior, 37(3), 424-451. doi:10.1177/1090198109342084

Daiski, I. (2007). Perspectives of homeless people on their health and health needs priorities. Journal of Advanced Nursing, 58(3), 273-281.

DeVerteuil, G. (2015). Conceptualizing violence for health and medical geography. Social Science \& Medicine, 133, 216-222.

Flicker, S., Maley, O., Ridgley, A., Biscope, S., Lombardo, C., \& Skinner, H. A. (2008). e-PAR: Using technology and participatory action research to engage youth in health promotion. Action Research, 6(3), 285-303. doi:10.1177/1476750307083711

Frankish, C. J., Hwang, S. W., \& Quantz, D. (2005). Homelessness and health in Canada: Research lessons and priorities. Canadian Journal of Public Health/Revue Canadienne de Santé Publique, 96( Suppl. 2),S23-S29.

Gaetz, S. (2004). Safe streets for whom? Homeless youth, social exclusion, and criminal victimization. Canadian Journal of Criminology and Criminal Justice/Revue Canadienne de Criminologie et de Justice Pénale, 46(4), 423-456. doi:10.3138/cjccj.46.4.423

Gaetz, S. (2013). Ending youth homelessness in Canada is possible: The role of prevention. In B. O’Grady, K. Buccieri, J. Karabanow, \& A. Marsolais, (Eds.), Youth homelessness in Canada: Implications for policy and practice (pp. 469-501). Toronto, ON: Canadian Homelessness Research Network Press.

Gaetz, S., Donaldson, J., Richter, T., \& Gulliver, T. (2013). The State of Homelessness in Canada 2013. Toronto, ON: Canadian Homelessness Research Network Press.

Galtung, J. (1990). Cultural violence. Journal of Peace Research, 27(3), 291-305.

Gil, D. (1999). Understanding and overcoming social-structural violence. Contemporary Justice Review, 2(1), 23-35.

Graziano, K. J. (2004). Oppression and resiliency in a post-apartheid South Africa: Unheard voices of black gay men and lesbians. Cultural Diversity and Ethnic Minority Psychology, 10(3), 302-316. doi:10.1037/1099-9809.10.3.302

Harley, D., Hunn, V., Elliott, W., \& Canfield, J. (2015). Photovoice as a culturally competent research methodology for African Americans. Journal of Pan African Studies, 7(9), 31-41.

Higgitt, N., Wingert, S., \& Ristock, J., Brown, M., Ballantyne, M., Caett, S., Coy, K., \& Quoquat, R. (2003). Voices from the margins: Experiences of street-involved youth in Winnipeg. Winnipeg, MB: University of Winnipeg. Retrieved from http://winnspace.uwinnipeg.ca/handle/10680/363

Hwang, S. W. (2001). Homelessness and health. Canadian Medical Association Journal, 164(2), 229-233.

Jeong, H.-W. (2008). Understanding conflict and conflict analysis. London, UK: Sage. 
International Journal of Child, Youth and Family Studies (2016) 7(1): 104-124

Karabanow, J. (2010). Street kids as delinquents, menaces and criminals: Another example of the criminalization of poverty. In D. Crocker \& V. M. Johnson (Eds.), Poverty, regulation and social exclusion: Readings on the Criminalization of Poverty (pp. 138-147). Halifax, NS: Fernwood.

Kelly, K., \& Caputo, T. (2007). Health and street/homeless youth. Journal of Health Psychology, 12(5), 726-736.

Kidd, S. (2007). Youth homelessness and social stigma. Journal of Youth Adolescence, 36(3), 291-299. doi:10.1007/s10964-006-9100-3

Leitch, R. (2006). Limitations of language: Developing arts-based creative narrative in stories of teachers' identities. Teachers and Teaching: Theory and Practice, 12(5), 549-569.

Levitas, R., Pantazis, C., Fahmy, E., Gordon, D., Lloyd, E., \& Patsios, D. (2007). The multidimensional analysis of social exclusion. (Project report). Bristol, UK: University of Bristol. Retrieved from http://roar.uel.ac.uk/1781/1/multidimensional.pdfNewbury, J., \& Hoskins, M. L. (2008). A meaningful method: Research with adolescent girls who use crystal methamphetamine. Child \& Youth Care Forum, 37(5), 227-240.

Newbury, J., \& Hoskins, M. (2012). Seeking solutions without centering problems: From research to practice. International Journal of Child, Youth and Family Studies, 3(1), $20-45$.

Nichols, N. (2013). Nobody "signs out of care”. Exploring institutional links between child protection services and homelessness. In B. O’Grady, K. Buccieri, J. Karabanow, \& A. Marsolais (Eds.), Youth homelessness in Canada: Implications for policy and practice (pp. 75-93). Toronto, ON: Canadian Homelessness Research Network Press.

O’Grady, B., \& Gaetz, S. (2009). Street survival: A gendered analysis of youth homelessness in Toronto. In J. D. Hulchanski, P. Campsie, S. Chau, S. Hwang, \& E. Paradis (Eds.), Finding home: Policy options for addressing homelessness in Canada, (pp. 1-28).Toronto, ON: Cities Centre, University of Toronto.

Ontario Poverty Reduction Strategy (2014). Realizing our potential: Ontario's poverty reduction strategy 2014 [Annual report]. Retrieved from https://dr6j45jk9xcmk.cloudfront.net/documents/4315/poverty-report-2014-en.pdf

Ozanne, J. L., \& Saatcioglu, B. (2008). Participatory action research. Journal of Consumer Research, 35(3), 423-439. doi:10.1086/586911

Powers, C. B., \& Allaman, E. (2012). How participatory action research can promote social change and help youth development. Kinder \& Braver World Project: Research series. Retrieved from https://cyber.law.harvard.edu/node/97242

Robinson, J. L. (2013). Youth homelessness and social exclusion: A "methods from the margins" approach. (Doctoral dissertation). Waterloo, ON: University of Waterloo. Retrieved from https://libuwspaceprd02.uwaterloo.ca/bitstream/handle/10012/7972/Robinson_Jennifer.pdf? sequence $=1 \&$ isAllowed $=y$ 
International Journal of Child, Youth and Family Studies (2016) 7(1): 104-124

Rudkin, J. K., \& Davis, A. (2007). Photography as a tool for understanding youth connections to their neighborhood. Children, Youth and Environments, 17(4), 107-123.

Silver, H., \& Miller, S. (2003). Social exclusion: The European approach to social disadvantage. Indicators, 2, 5-21. doi:10.1080/15357449.2003.11069166

Springer, J., Lum, J., \& Roswell, T. (2013) Policy challenges to homelessness among Caribbean youth in Toronto. In B. O’Grady, K. Buccieri, J. Karabanow, \& A. Marsolais (Eds.), Youth homelessness in Canada: Implications for policy and practice (pp. 445-468). Toronto, ON: Canadian Homelessness Research Network Press.

Torre, M. E., \& Fine, M. (2006). Participatory action research (PAR) by youth. In L. R. Sherrod, C. A. Flanagan, R. Kassimir, \& A. Syvertsen (Eds.), Youth Activism: An International Encyclopaedia (Vol. 2, pp. 456-462). Westport, CT: Greenwood Publishing Group.

Ungar, M. (2005). Pathways to resilience among children in child welfare, corrections, mental health and educational settings: Navigation and negotiation. Youth and Child Care Forum, 34(6), 423-444.

Votta, E., \& Manion, I. (2004). Suicide, high-risk behaviors, and coping style in homeless adolescent males’ adjustment. Journal of Adolescent Health, 34(3), 237-243. doi:10.1016/j.jadohealth.2003.06.002

Wang, C. C., Cash, J. L., \& Powers, L. S. (2000). Who knows the streets as well as the homeless? Promoting personal and community action through photovoice. Health Promotion Practice, 1(1), 81-89. doi:10.1177/152483990000100113

Whitbeck, L. B., Hoyt, D. R., Yoder, K. A., Cauce, A.M., \& Paradise, M. (2001). Deviant behaviour and victimization among homeless and runaway adolescents. Journal of Interpersonal Violence, 16(11), 1175-1204. doi:10.1177/088626001016011005

Wilson, N., Dasho, S., Martin, A., Wallerstein, N., Wang, C., \& Minkler, M. (2007). Engaging young adolescents in social action through photovoice: The Youth Empowerment Strategies (YES!) project. The Journal of Early Adolescence, 27(2), 241-261. doi:10.1177/0272431606294834 